\title{
EL PESO DE LA MATERIALIDAD EN LA ESCRITURA Y EL PENSAMIENTO DE JACQUES DERRIDA
}

\author{
GUSTAVO BUSTOS GAJARDO \\ Universidad de Chile
}

\begin{abstract}
RESUMEN: Rastrear en la escritura de Jacques Derrida la existencia de un pensamiento otro de la materialidad no es tarea sencilla. Sin embargo, es la tarea que se propone delinear, al menos en sus coordenadas generales, el presente artículo. Ello, inicialmente, implicaría seguir una serie de elementos propios de la tradición presocrática que estarían inscritos a modo de huellas en la escritura deconstructiva. En tal sentido, nociones como las de átomo, vacío y movimiento serán consideradas, en diversos momentos del presente texto, en el marco de una interpretación contemporánea de la divisibilidad y fragmentación de lo existente. A partir de estas consideraciones y su relación con la escritura en el pensamiento de la deconstrucción se sostendrá el carácter cuasi-trascendental de la materia.
\end{abstract}

PALABRAS CLAVE: materialidad; escritura; idealismo; átomo; vacío, movimiento.

\section{The heft of materiality in the writing and the thinking of Jacques Derrida}

ABSTRACT: It's not a simple task to trace in Jacques Derrida's writing the existence of thought other the materiality. However, in this article, I will try to outline at least Derrida's more general thinking. At the start, this involves following those more traditional elements of thought, typically associated with the pre-Socratic tradition, usually found inherently in Derrida's deconstructive writing. Therefore, in this context, I will examine such notions as those of atoms, vacuum as well as movement included in different times and within contemporary frameworks and understanding of the divisibility and fragmentation of existence. I intend to examine these considerations and their relationship with deconstructive writing in order to establish the quasi-transcendental nature of matter.

KEY WORDS: materiality; writing; idealism; deconstruction; atom; vacuum; movement.

«La lucha entre el idealismo y el materialismo, ¿ha podido envejecer en los dos mil años de evolución de la filosofía? $¿$ ¿Ha envejecido la lucha entre las tendencias o las directrices de desarrollo de Platón y Demócrito?»

Lenin, V. I. Materialismo y empiriocriticismo, p. 158.

\section{1. ¿UN NUEVO MATERIALISMO O UN PENSAMIENTO OTRO DE LA MATERIALIDAD?}

En 1986, Kadhim Jihad, en una entrevista recopilada en No escribo sin luz. artificial, le preguntaba a Jacques Derrida sí era posible considerar «sus trabajos como una contribución al materialismo» ${ }^{1}$. En su respuesta, el filósofo

1 DERrida, J., «Del materialismo no dialéctico. Entrevista con Kadhim Jihad». Diario 16, Culturas, 1986, n69, IV. Esta entrevista, publicada originalmente en español, fue posteriormente recopilada bajo el título «En el límite de la traducción» en No escribo sin luz artificial. Cuatro Ediciones, Valladolid, 1999, pp. 37-48. 
franco-magrebí, retomando un hilo adelantado en una entrevista de 1971 realizada por los telquelistas Jean-Louis Houbedine y Guy Scarpetta², admitía la existencia de una filiación entre una cierta concepción del materialismo y su pensamiento de la deconstrucción. Aun cuando Derrida no habría explicitado del todo los rasgos específicos de dicha filiación, en ambas entrevistas señalaba la necesidad de adherirse, en principio y con mucha cautela, a los «materialistas griegos $»^{3}$ o, lo que viene a ser lo mismo, a un pensamiento preplatónico o presocrático de la materialidad. A contracorriente de los esquemas eidéticos de la tradición filosófica inaugurada por Platón, la herencia presocrática le habría permitido a Derrida entender la materia no como una "presencia sustancial», sino como aquello que se «resiste a la reapropiación» e idealización metafísica ${ }^{4}$. Resistencia, en suma, cuya finalidad sería evitar que la materia llegase a constituir, como ha ocurrido de Aristóteles en adelante ${ }^{5}$, «un nuevo

2 Derrida, J., «Positions. Entretien avec Jean-Louis Houdebine et Guy Scarpetta» en Positions. Les Éditions du Minuit, Paris, 1972a, pp. 51-126. Esta entrevista fue inicialmente publicada en la Revue Promesse, no 30-31 de 1971. Entre 1960 y 1982 se publica en Francia la Revista Tel Quel. La revista surgió como un espacio de reflexión y expresión externo a la universidad, pero comprometida con una transformación de la escena teórica francesa mediante, en parte, la necesidad de consolidar una teoría de la escritura hasta ese momento inédita y, por otra, apuntalar una reflexión política que extienda los efectos de mayo del '68. A los miembros de la revista y sus colaboradores se les conoce bajo el apelativo de "telquelistas" y entre ellos se destacan las siguientes figuras: Phillipe Soller, Michel Deguy, Jean-Louis Baudry, Jean-Pierre Faye, Jacqueline Risset, y Julia Kristeva, quienes entre otros fueron miembros del Comité de redacción, y otros que fueron destacados colaboradores y cercanos al proyecto teórico-estético de la revista como son los casos de Roland Barthes, Georges Bataille, Jacques Derrida, Michel Foucault, Tzvetan Todorov, Francis Ponge, Jean-Luc Godard y Maurice Blanchot entre otros. Para una historia de la Revista Tel Quel en español se puede consultar Asensi, M., Los años salvajes de la teoría. Philippe Sollers, Tel Quel y la génesis del pensamiento post-estructural francés (Valencia: Tirant lo Blanch, 2006).

3 Cf. Derrida, J. op. cit., 1972a, p. 100. Cf. También Derrida, J., «Nous autres grecs» en CAssin, B., Nos grecs et leurs modernes. Les stratégies contemporaine d'appropiation de l'antiquité. Éditions du Seuil, Paris, 1992, p. 253, nota al pie n 2.

4 Derrida, J. op. cit., 1986, IV o página 43 de En el límite de la traducción.

5 Al respecto habría que destacar, como lo consigna Heinz Wismann, que la mayoría sino todas las interpretaciones que se realizan respecto del pensamiento democriteano se basan en la retraducción que Aristóteles hiciera de los términos con los que Demócrito designaba las propiedades del átomo: el «ritmo» (rhusmos), en cuanto primera propiedad del átomo, fue traducida por Aristóteles como "forma» (morphè), "figura» y "esquema» (schè$m a$ ); el término tropè — dirección u orientación- que en Demócrito designaba, en estricto rigor, el cambio de orientación de los átomos fue sustituido por el término "posición» (Thèsis); y finalmente, el tercer principio del átomo, el «contacto» o diathigè, fue reemplazado por Aristóteles por la noción de «orden» (taxis). En consecuencia, como señala Wismann, desde Aristóteles se «sustituyen tres términos que designaban un movimiento por otros tres que, a partir de ese momento, son estáticos y describen algo de un orden espacial» (WismanN, H., Les avatars du vide. Démocrite et les fondements de l'atomisme. Hemann éditeurs, Paris, 2010, p. 9). Los efectos de esta retraducción sobre las interpretaciones que se realizan respecto del atomismo son incalculables en la historia de la filosofía, pues, incluso se pueden observar en la tesis doctoral de Marx, quien termina por reproducir el lenguaje de Aristóteles. Althusser, 
principio fundamental» que, al restituirle un «significado trascendental» a la noción de materia, aseguraría una vez más la emergencia de un «materialismo metafísico ${ }^{6}$. Es decir, la apuesta derrideana, bajo los signos de esta resistencia, implicaría hacer tambalear las simientes y los cimientos sobre los cuales se edifica el carácter trascendental de las ideas, sin que ello, por cierto, quiera decir que se pueda romper completamente con las fuentes de la idealidad ${ }^{7}$. Pero ¿permite esto afirmar la existencia en Derrida de un pensamiento de la materialidad que, a su vez, pueda apropiarse y exceder, al mismo tiempo, la forma de la idea?

Establecer una respuesta a dicha pregunta, sin duda no es cosa fácil. Sin embargo, las huellas de una tal posibilidad existen y se diseminan de un lugar a otro, de referencia en referencia y de texto en texto. En tal sentido, figuras como las de Empédocles, Leucipo y Demócrito - posteriormente reinscritas en las obras de Epicuro y del poeta y filósofo romano Lucrecio- habrían sido clandestinamente inoculadas por Derrida en su pensamiento con tal de objetar el esquema jerarquizado y dual de la metafísica. "El espectro de estos griegos», que permanece medianamente oculto al tiempo que desplaza constantemente los límites de la verdad, habría sido producido en el mismo instante en que la división del acto inaugural consiente su acontecimiento. Es decir, aun cuando sea posible rastrear, seguir y sumergirse en las fuentes y las derivas presocráticas de la deconstrucción, aquellas que mediante sus huellas autorizarían constatar un pensamiento de la materialidad en Derrida, este modo de pensar sólo podría desplegarse, más allá de la dialéctica entre ser y no-ser, por medio de la performatividad de sus condiciones de posibilidad, esto es, re-marcando en el texto el momento de su acontecimiento ${ }^{8}$. La afirmación contextual, contingente e incluso espectral de esta herencia le permitirían a Derrida, ahí donde «el constatativo es el performativo mismo», escribir prolépticamente la materialidad. Esta anticipación que dirige la escritura, en su ritmo y sus múltiples modos de inscripción, objetaría entre otras la anamnésica ${ }^{9}$ propuesta de Catherine

por su parte, considerando las interpretaciones de Marx habría optado, en consecuencia, por iniciar su recorrido con Epicuro, desconsiderando así elementos de suma importancia que se encontrarían en el eximio ciudadano de Abdera. Aunque no es el objeto de este artículo, vale señalar, al menos a modo de hipótesis de lectura, que en el pensamiento de Jacques Derrida no se daría lugar a semejante oclusión.

6 Derrida, J., Positions, op. cit., p. 88.

7 Cf. al respecto: Derrida, J., "Une idée de Flaubert: "La lettre de Platon"» en Psyché. L'invention de l'autre. Éditions Galilée, Paris, 1987-1988, pp. 305-325. [Trad. Pavez, Javier y Thayer, Cristóbal. "Una idea de Flaubert. "La carta de Platón”» en Psyché. Invención del otro. Adrogué, Ediciones La Cebra; 2016, pp. 335-356].

8 Derrida, J., Psyché. L'invention de l'autre en Psyché, op. cit., pp. 23 y 24 [Trad. Cragnolini, Mónica. Psyché. Invención del otro. La Cebra, Adrogué, 2016, p. 26].

9 Si bien las diferencias entre Malabou y Derrida ameritarían la escritura exclusiva de un artículo, acá tan sólo dejaremos esbozados algunos parámetros que permitan justificar un acceso a la materialidad desde la perspectiva cuasi-trascendental sostenida por Derrida en desmedro de la aproximación kantiana de Malabou a lo trascendental. Dicho esto, vale explicar, al menos sucintamente, por qué se califica la propuesta de Malabou de anamnésica. 
Malabou de «encaminar la deconstrucción hacia un nuevo materialismo» ${ }^{10}$. A diferencia de Malabou, quien asienta y defiende la plasticidad como un «esquema hermenéutico motor»e intencional del materialismo futuro, capaz de trascender las limitaciones de la escritura y lo que ella consigna como su consiguiente incapacidad de pensar la materialidad de la materia ${ }^{11}$, lo que aquí en

Como Malabou ha dejado claramente establecido en diversos textos, la plasticidad remite siempre a la presencia de una condición formal a priori que tiene en sí tanto la capacidad de recibir y dar como la de designar la explosión de una forma cualquiera. Esto quiere decir que la capacidad auto-diferenciante de la forma mediante la plasticidad es, en tal sentido, su condición trascendental y, aunque esta se puede leer como una crítica al innatismo platónico — razón por la que no trata de recordar una forma [Eidos] original e inteligible como lo preformado que ha sido olvidado-, ella, sin embargo, trata inevitablemente de no abandonar lo trascendental en el marco de la formación de su posteridad. Lo trascendental existe avant demain en cuanto condición de posibilidad de lo que todavía no existe en el espacio sensible. En el caso de la escritura de Derrida, la síntesis cuasi-trascendental, como señala certeramente Rodolphe Gasché, «representa la corrupción necesaria de las idealidades, o trascendentales de todo tipo... en el momento mismo de su constitución» (p. 274). Volveremos sobre este punto más adelante. Respecto de lo señalado en torno a Malabou ver: Malabou, C., Avant demain. Épigenèse et rationalité. P.U.F, Paris, 2014. Respecto de lo cuasi-trascendental en Derrida, ver: Derrida, J., Glas. Éditions Galilée, Paris, 1974 [especialmente la columna izquierda]; DERRIDA, J., «Entre crochets (I)» $\mathrm{y}$ «Ja, ou le faux-bond» en Points de suspension. Entretiens. Éditions Galilée, Paris, 1992. Gasché, R., «Literature or Philosophy?» en The Tain of the Mirror. Derrida and the Philosophy of Reflection. Harvard University Press, USA, 1986.

10 Malabou, C., La plasticité au soir de l'écriture. Éditions Léo Scheer, Paris, 2004, p. 114. [Trad. Javier Bassas y Joana Masó. La plasticidad en el atardecer de la escritura. Ellago Ediciones, Castellón, 2008]. Cf. también Malabou, C., La plasticidad en espera. Editorial Palinodia, Santiago, 2010.

11 La posición defendida por Malabou, analizada en detalle por GolDGABER, D., en «The Plasticity of. Writing»: Malabou on the Limits of Grammatology, se sostiene sobre la base, a nuestro juicio, de un diagnóstico equivocado respecto del fracaso de la escritura en relación al materialismo, pues Malabou inicia su crítica desconsiderando que «la forma es ya una cierta huella de la diferencia», es decir, olvida o no quiere ver que la escritura, más allá de la distinción entre forma y materia tratada por Derrida en su Introducción al Origen de la Geometría, es siempre una modificación de la forma y, en cuanto tal, cada modificación es, a su vez, una inscripción material. Para ilustrar adecuada y pormenorizadamente lo que podría calificarse como la diferencia clave entre Malabou y Derrida haría falta la escritura de un artículo dedicado en exclusiva a dicho punto, sin embargo, esto es algo que dejaremos pendiente hasta nuevo aviso. Por otra parte, habría que inscribir este debate con relación al problema de la temporalidad, pues la materialidad no sería un tema independiente a la cuestión de la génesis [al respecto ver, Trujillo, I., "La digresión: Malabou, Derrida y el concepto vulgar del tiempo (Aproximación al problema de la inactualidad de Hegel)» en: Revista de Humanidades, Universidad Andrés Bello, núm.39 (enero-junio 2010) pp.165185)]. Por ahora, a modo de referencia, se consigna para el lector interesado algunos de los textos que habría que considerar como bibliografía secundaria respecto del tema en cuestión: BARAD, K., Meeting the Universe Halfway: Quantum Physics and the Entanglement of Matter and Meaning. Duke University Press Durham, 2007. Claire Colebrooke, "Matter without Bodies». Derrida Today 4, no. 1 (2011). Brenda Bandhar and J. Goldberg-Hiller (ed) Plastic Materialities: Politics, Legality, and Metamorphosis in the Work of Catherine Malabou. Duke University Press, Durham, 2015. Thomas Wormald and Isabell Dahms (ed). 
adelante se propone es leer con Derrida el carácter cuasi-trascendental de un pensamiento otro de la materialidad.

\section{LA IDEALIDAD Y LO OTRO DEL PENSAMIENTO}

Explicitar lo que podría significar un pensamiento otro de la materialidad a partir de los escritos de J. Derrida exigiría, en principio - pero sólo en principio-, reconocer en su pensamiento una multiplicidad de fragmentos comúnmente excluidos del sistema filosófico. En las distintas etapas de la historia occidental, cuestión que no debe perderse de vista, estos fragmentos habrían sido violentamente negados con la finalidad de favorecer una tendencia hegemónica en la que se impone lo Uno de la existencia contra la multiplicidad de lo existente. Si bien, gran parte de las tendencias materialistas se habrían organizado filosóficamente en una tenaz oposición ante este leitmotiv de la metafísica occidental, la mayoría de sus estrategias quedarían relegadas a ser el polo negativo en toda pareja de opuestos. La primacía del vector idealista niega, pero no borra del todo, la condición material sobre la cual se sostiene. Por tanto, no ha de resultar extraño encontrar, en este contexto, diversos rastros conceptuales desperdigados en siglos de filosofía que permiten afirmar, como lo hará Derrida, una concepción no metafísica de la materia. Concepción que podría calificarse como el mayor efecto de la inversión del platonismo. En palabras de L. Althusser, Derrida sería el máximo exponente contemporáneo, junto a Deleuze, de una camada de filósofos que serían, ni más ni menos, que las eximias figuras de la "verdadera tradición materialista en filosofía ${ }^{12}$. Todas estas figuras, incluido Derrida, tendrían en más de un punto una relación indisociable con las concepciones presocráticas de la materia.

En el caso de Jacques Derrida, como señalábamos al inicio de este artículo, la relación con una concepción presocrática de la materia habría sido temprana, pero oblicuamente, reconocida. En términos cronológicos es recién en una conferencia de 1982 titulada Mes chances $^{13}$ donde reconocerá de un modo más abierto dicha filiación. Sin embargo, es preciso señalar con todas sus letras que habría previamente admitido, en el contexto de su crítica de la metafísica, que lo que él escribe bien podría ser considerado desde el punto de vista de un texto

Thinking Catherine Malabou. Passionate Detachments. Rowman \& Littlefield International, USA, 2018. Cristóbal Durán. La soltura del cuerpo. Indiferencias de la diferencia en Catherine Malabou. Ediciones Metales Pesados, Chile, 2018. Cabe destacar que la mayoría de los textos consignados en esta nota bregan, en su mayoría, a favor de la plasticidad, lo que no significa que se distancien realmente de la noción de escritura de Jacques Derrida.

12 Althusser, L., «L'unique tradition matérialiste», Revue Ligne, n. 8, pp. 72-119, Éditions Hazan, Paris 1993, p. 102.

13 DERRIDA, J., «Mes chances. Au rendez-vous de quelques stréréophonies épicuriennes» en Psyché, op. cit., pp. 353-384 [Trad. Gil, Sol. «Mis chances. Encuentro con algunas estereofonías epicúreas» en Psyché, op. cit., pp.385-424]. 
materialista ${ }^{14}$. Lo fundamental, en ambos casos, es que su pensamiento no permite afirmar, como ocurre en la mayoría de los materialismos filosóficos ${ }^{15}$, un modo de ser de la materia. "Que el concepto de materia sea en sí un concepto metafísico» 0 "un concepto en sí no-metafísico ${ }^{16}$ depende en cada caso, señala Derrida, de cómo se trabaje cada concepto. Es más, no importa realmente desde qué lado de la oposición entre lo trascendental y lo empírico se trabaje un concepto - una experiencia o una cosa- pues este siempre «da lugar a una doble lectura y a una doble escritura $»^{17}$. El encuentro entre una lecto-escritura metafísica, logocéntrica, idealista, trascendental e inteligible, en este caso de la materia, con una lectura no-metafísica, patética, materialista, empírica y sensible de la misma, en efecto, es siempre posible/imposible en su acontecimiento. Asumiendo con toda claridad esta premisa es que Derrida tempranamente señaló que su pensamiento —objetando algunas reservas esbozadas por Christine Glucksmann en el célebre coloquio Littérature et ideologie ${ }^{18}$ celebrado en 1970 - en absoluto tenía la intención de borrar la lucha entre materialismo e idealismo. El hecho de no borrar esta lucha no implicaba para él reproducirla como sistema, ni tomar partido por las formas argumentativas hasta ese momento vigentes. No obstante, mediante una inteligente treta retórica, Derrida respondía preguntando a sus interlocutores si acaso debía recordarles contra qué estaba intentado sistematizar la crítica deconstructiva, afirmando

14 Derrida, J., Positions, op. cit., p. 87.

15 Entre las manifestaciones más reconocidas de los materialismos filosóficos se encuentran el atomismo, el fisicalismo, el positivismo, el materialismo moral o práctico, la fenomenología materialista, el materialismo dialéctico y el materialismo histórico. El problema es que estas expresiones de lo material compartirían, cada uno desde su propio modo de ser, una suerte de vinculo indisociable con las pretensiones de una ontología general que se expresaría de común acuerdo en una crítica a la tesis de la unicidad del ser. En tal dirección, la marca que se repetiría en uno y otro de estos materialismos es la Idea de una pluralidad indeterminada que niega el carácter estático de ordenamiento universal. Sin embargo, a cada uno de ellos le correspondería a su vez una ontología especifica que se edificaría siempre sobre el prototipo de una unidad ontológica real del mundo. Ocurre, entonces, que las ontologías especificas invaden y neutralizan el carácter universal de la ontología general y, esta última, sin embargo, permitiría la pluralidad de ideologías que se encuentran en su seno y que, por tanto, delimitarían las aventuras de la materialidad. Cf. LANGE, F., Historia del materialismo, Editorial Daniel Jorro, Madrid 1903; Charbonnat, P., Histoire des philosophies matérialiste, Éditions Kimé, Paris 2013.

16 Derrida, J., Positions, op. cit., p. 88.

17 Derrida, J., La dissémination, Éditions du Seuil, Paris 1972, p. 10.

18 Barberi, P.; Kristeva, J. et. al. Colloque de Cluny: Littérature et ideologie, La nouvelle critique, Paris 1970 [Trad. Socorro, Thomas. Literatura e ideologías, Alberto Corazón, Madrid 1972. Cabe señalar que las reservas planteadas por Glucksmann no figuran en el corpus textual de su exposición titulada Sur la rélation Littérature et idéologies, sino estas figuran en las discusiones que se dieron posteriormente. Es importante señalar que Derrida no asistió a dicho coloquio, sin embargo, supo de estas discusiones por medio de las Actas de este, y respondió a las objeciones Glucksmann en Positions. En la traducción al español que aquí se consigna, lamentablemente, no fueron consideradas estas discusiones para el establecimiento del texto. 
en la misma pregunta que esta se dirigía "precisamente contra la autoridad del sentido, como significado trascendental o como telos», es decir, que su pensamiento se organizaba contra «la historia en su representación logocéntrica, metafísica, idealista» ${ }^{19}$. No contento con este planteamiento, Derrida agregaba, un poco más adelante, con la intención de disipar cualquier duda al respecto, que no sólo estaba interesado por «ciertas formas de materialismo mecanicista» sino que «el desmonte del logocentrismo es simultáneamente —a fortioriuna deconstitución del idealismo o del espiritualismo en todas sus variantes ${ }^{20}$. Sí, como es afirmado ahí, «el logocentrismo también es, fundamentalmente, un idealismo $»^{21}$, entonces, en ningún caso $s u$ deconstrucción podía ni puede ser considerada como un intento de borrar la lucha contra el idealismo.

A pesar de que esta lucha contra el idealismo es uno de los trasfondos materialistas menos explorados que atraviesa todo el pensamiento de J. Derrida, no deja de ser evidente que son numerosos los vestigios que tendríamos que seguir una vez que las oposiciones han perdido su pertinencia ${ }^{22}$. Es por ello que, como sostuvo Derrida, habrá que inscribir dos veces el concepto de materia, marcarlo «en el campo deconstruido, ésta es la fase de inversión, y en el texto deconstruyente, fuera de las oposiciones en las que ha estado preso ${ }^{23}$. Teóricamente esto quiere decir que no existe idealidad alguna que sea ajena a la inscripción que la posibilita: «el acto de escritura», en tanto "algo no se deja idealizar o reapropiar ${ }^{24}$, constituye «la más alta posibilidad de toda 'constitución'» del texto, siempre y cuando sea también la condición de su imposibilidad.

Un texto materialista, dicho lo anterior, es aquel que «apela —en palabras de Noelia Billi- a un modo de comprender la efectualidad toda de la existencia de manera fragmentaria ${ }^{25}$. Explicitar, por tanto, a partir de los escritos derrideanos lo que podría significar un pensamiento otro de la materialidad exigiría, en principio - pero sólo en principio-, reconocer aquellos fragmentos que han sido constantemente excluidos del sistema filosófico occidental, pero que han caído, a causa de su propio peso, en su escritura como «una marca [que] no esté necesariamente vinculada, ni siquiera bajo la forma del reenvío, a un sentido o a una $\operatorname{cosa} »^{26}$. Lo que no existe al modo de una cosa o un significado determinado,

19 Derrida, J., Positions. op. cit., p. 67

20 Ibid., p. 70.

21 Ibidem.

22 Cf. Derrida, J., La dissémination. Éditions du Seuil, Paris, 1972, p. 367 [Traducción Arancibia, José María. La diseminación. Editorial Fundamentos, 32007, p. 493].

23 Derrida, J., Positions, op. cit., p. 88.

24 Derrida, J., Del materialismo no dialéctico..., op. cit., p. V.

25 Billi, N., "Materialidad y agujeros sin espíritu: Artaud entre Blanchot y Derrida». Aisthesis [online]. 2017, n.61 [citado 2018-09-10], pp. 9-23. ISSN 0718-7181. Disponible en: http://dx.doi.org/10.7764/aisth.61.1.

26 DerRida, J., «Mes chances. Au rendez-vous de quelques stréréophonies épicuriennes» en Psyché, op. cit., p. 367 [Trad. Gil, Sol. «Mis chances. Encuentro con algunas estereofonías epicúreas» en Psyché, op. cit., p. 405]. 
existe, en lo que Derrida considera su interpretación del stoikheion, como una marca o una huella no necesariamente sensible que lo transforma todo. Este elemento [stoikheion], marcado y remarcado por Derrida a partir de «la divisibilidad de la marca», acontece como una suerte de retorno de aquel pensamiento materialista que históricamente ha sido reprimido, pero que en él se esbozaría, iteradamente, en su diseminación. En cualquier caso, este conjunto no homogéneo de fragmentos no puede ser reducido, simple y llanamente, a un conjunto de elementos sustanciales que restrinjan la materialidad al vínculo entre la deconstrucción y la concepción presocrática de la materia.

Otros elementos, ligados a la fenomenología, la literatura, el psicoanálisis y la lingüística, también hacen parte del repertorio que permite leer a Derrida como un pensador materialista. Desde este punto de vista, la crítica a la metafísica de la presencia constituye, en su inconstitucionalidad, «una intervención» que facilita a lo otro de la filosofía "escribir su interpretación $»^{27}$ y, con ello, inscribir, en la división misma de un territorio a ser explorado, «una lógica distinta a la lógica del $\log o s »^{28}$. En consecuencia, es sólo a partir o mediante un razonamiento híbrido o bastardo [logismô nothô] que lo otro del pensamiento tiene alguna chance de acontecer "más allá de las oposiciones categoriales» ${ }^{29}$.

La escritura de esta posibilidad, en el contexto abierto por este razonamiento bastardo, al que alude Derrida a propósito del Timeo de Platón ${ }^{30}$, no implicaría per se negar ni oponer eso otro a la idealidad del pensamiento. Tampoco implicaría, siguiendo un trayecto inverso, afirmar que Derrida ha, stricto sensu, re-escrito la noción de materialismo. Aquello que en realidad puede reconocerse y que no ha dejado de trazarse en su escritura, como ya se ha señalado, no es otra cosa sino el anuncio y la diseminación ficcional de la materialidad. De ahí que un pensamiento otro de la materia, tal y como en parte había sido planteado por los presocráticos, exija a las reflexiones contemporáneas desandar aquellas estrategias filosóficas que sostienen que la materia se restringe a la esfera de lo extenso, lo calculable, lo visible ${ }^{31}$. La escritura, siendo para Derrida una de las manifestaciones sensibles de la idealidad, pone en marcha una actividad afirmativa del pensamiento que, al reconocerse como "átomo irreductible», no puede permitirse pensar lo material a partir de nociones ingenuas, menos aun

27 Derrida, J. y Ferraris, M., El gusto del secreto, Amorrortu, Buenos Aires 2009, p. 47.

28 Vernant, J.-P., Mythe et société en Grèce ancienne. Maspero, París, 1974, p. 250 [Traducción: Mito y sociedad en la Grecia antigua. Siglo XXI editores, Madrid, ${ }^{4} 2003$, p. 220]. Esta cita es retomada posteriormente por Derrida en Khôra.

29 Derrida, J., Khôra. Éditions Galilée, Paris, 1993, p. 17 [Traducción Pons, Horacio. Khôra. Buenos Aires, Amorrortu, 2011, p. 17].

30 Cf. Derrida, J., La dissémination. Éditions du Seuil, Paris, 1972, pp. 96, 164, 171, 174, 186 [Traducción Arancibia, José María. La diseminación. Editorial Fundamentos, ${ }^{3} 2007$, pp. 126, 216, 225, 245]; Derrida, Jacques. Khôra. op. cit., 1993, pp. 17, 38, 68, 90, 92, 94; Derrida, Jacques. "Cómo no hablar. Denegaciones» en Cómo no hablar y otros textos. Proyecto a ediciones, Barcelona, 21997, pp. 25, 37.

31 Cf. BILli, N., «La cosa escrita. Materialismo y lenguaje en Maurice Blanchot». Revista Actuel Marx / Intervenciones, $\mathrm{N}^{\circ}$ 16, Primer semestre, 2014, pp. 69-89. 
cuando en su seno se siga reproduciendo acríticamente la lógica del binarismo: la escritura, en su interminable revolución, contamina y vuelve impuro lo inteligible ${ }^{32}$, lo trascendental, pero también corrompe lo sensible y lo empírico. La escritura y la materialidad no llegan a ser, por tanto, ni sensibles ni inteligibles, pero participan, al mismo tiempo, de ambos registros tal y como sucede, por ejemplo, con las cuasi «nociones» de himen, différance, resto y otras tantas en Derrida. Y es precisamente en virtud de esta situación que Derrida hace constantemente resonar en su pensamiento aquello que la tradición occidental ha silenciado. Las figuras sensibles, como lo señala en La mythologie blanche, se esconden entre las nociones abstractas ${ }^{33}$ e inteligibles con las que se pretende blanquear los exergos del texto materialista y, a partir de este blanqueamiento la tradición pretende elaborar y defender un pensamiento inmaculado. Esta pretensión deja en estas nociones, no obstante, una marca que aparece tan sólo al desaparecer la experiencia sensible. En la desaparición se produce - ahí el elemento atómicamente irreductible de la deconstrucción - una especie de resistencia hylética de lo sensible que parasita el campo trascendental e inteligible.

Como el mismo Derrida observa y destaca retroactivamente, al escribir en 1990 el prólogo para la publicación de su Memoria de 1953-1954 $4^{34}$, su trabajo «trata siempre de una complicación originaria, de una contaminación de lo simple, de una distancia inaugural que ningún análisis sabría presentar» ${ }^{35} \mathrm{y}$ que incide, por ello mismo, en la conformación de la idealidad. «Considerado en tanto que tal», el problema de la génesis le permitirá a Derrida, en su calidad de fenomenólogo ${ }^{36}$, encontrar, en términos heterodoxos en relación con la ortodoxia husserliana, una vía particular de acceso «al corazón de las grandes y clásicas cuestiones de la objetividad, de la validez de los fundamentos, del devenir histórico, de las relaciones de la forma y la materia, de la actividad y la

32 Lévinas ha cuestionado que la materia pertenezca tan sólo a la dimensión de lo visible, y que lo visible se constituya como criterio rector tanto en el ámbito de la extensión como de la inteligibilidad. Cf. Lévinas, E., Totalité et Infini, Essai sur l'extériorité. M. Nijhoff, L'Haya, 1961.

33 Derrida, J., Marges - de la philosophie. Les Éditions du Minuit, Paris, 1972, p. 250.

34 DERRIDA, J., Le problème de la genèse dans la philosophie de Husserl. P.U.F, Paris, 1990. Este texto se publicó en 1990 pero corresponde a la tesis de 1953-1954 con la que Derrida obtuvo su Diploma de Estudios Superiores en la ENS bajo la dirección de Condillac. Permaneció inédito hasta 1990.

35 Ibid., p. 7.

36 Filósofos como Rudolf Bernet, Françoise Dastur, Paola Marrati-Guénoun, Bernhard Waldenfels, Patricio Peñalver, Iván Trujillo, Valeria Campos Salvaterra, entre otros, suelen destacar la relación de J. Derrida con la fenomenología. Aunque cada uno lo hará desde diferentes prismas, es frecuente que se destaque la importancia del pensamiento de Husserl para Derrida. Al respecto, Patricio Peñalver sostiene que «la fenomenología de Husserl es seguramente la fuente intelectual más eficaz teóricamente en la construcción del pensamiento de Derrida». Peñalver, P., La desconstrucción. Escritura y diferencia. Montesinos editor, Barcelona, 1990, p. 44. 
pasividad, de la cultura y la naturaleza ${ }^{37}$. En este contexto, preguntarse por la génesis de la materialidad, siempre y cuando no se pierda de vista que las condiciones trascendentales capitanean las posibilidades de la génesis histórica, constituye nada más ni nada menos que un primer acceso a la deconstrucción del idealismo y sus garantías constitucionales. Y son precisamente estas garantías o condiciones, en la medida en que la fenomenología husserliana parece ser una versión moderna del platonismo, pero también del hegelianismo, las que Derrida comienza a interrogar incesantemente a través de los distintos textos que de ahí en adelante publicó. Asimismo, un segundo interés por la génesis en el marco de los textos de raigambre fenomenológica, especialmente los publicados entre 1953 y 1962, tiene que ver con la relación entre filosofía e historia. En aquellos textos se inscriben los prolegómenos de toda una discusión y distanciamiento respecto del valor de la dialéctica. Aunque Derrida en estos textos no renunciará del todo a ella, si adelantará que en su seno persiste una "no-dialéctica», un remanente sin relevo, que la constituiría trascendentalmente. La proposición de una génesis trascendental se desplegará, poco a poco, como el antecedente del posterior cuasi-concepto de différance.

Ahora bien, Derrida acotará que «la debilidad de las grandes dialécticas y de las grandes filosofías del devenir» (el platonismo y el hegelianismo, por una parte y, de otra, el materialismo dialéctico) se localizaría en su excesivo formalismo, pues, a través de este, estas habrían operado siempre a partir de una oposición ya formalizada de la forma contra la materia y del sentido contra lo sensible. Estas oposiciones configurarían las posibilidades, entre otras, de constituir la filosofía en un sistema tradicional donde génesis (historia) y estructura (idea) se integrarían pasivamente en el devenir de un proceso genético. Las estructuras ideales, según Husserl, tendrían por ello un carácter temporalmente predefinido. Derrida radicalizará esta tesis al señalar que toda génesis debe siempre-ya estar allí para producirse. Por tanto, a diferencia de Husserl, entenderá que una estructura ideal no puede separarse de sus condiciones materiales y, por tanto, que ella no estaría sometida a un origen pleno. Este proceso, en pocas palabras, implicaría que, a partir de una "síntesis $a$ priori ${ }^{38}$, seríamos reenviados a una dialéctica infinita. Sin embargo, en aquel momento genético del pensamiento derrideano, el problema de la materialidad no estaría, todavía, inscrito en las coordenadas de la escritura. En términos cronológicos, será recién con la Introducción a su traducción de L'origine de la géométrie de Husserl que escritura y materialidad se entretejerán. Por tanto,

37 DERRIDA, J., Le problème de la genèse..., op. cit., p. 2. Las cursivas son del autor de este artículo.

38 La cuestión de la síntesis a priori habría que rastrearla más allá de Husserl. Habrá sido Kant quien En la crítica de la razón pura establecería que el conocimiento tiene su fuente en la experiencia, sin embargo, dirá también que es necesario, para que la experiencia sea posible, que algo no dependa de ella. Los conocimientos a priori serían, en consecuencia, independientes de la experiencia. Cf. Kant, I., Crítica de la razón pura. Taurus, Madrid, 2002, pp. 41-44. 
lo que estaría en juego, en la génesis de un tema y el tema de la génesis, sería entre otras cosas que la filosofía de la historia y la historia de la filosofía son en cierto modo inseparables. La fuerza del argumento derrideano estaría en el proceso de desmantelamiento del concepto de génesis, lo cual se traducirá retroactivamente en que «el momento originario de la génesis que constituye el sentido deberá ser a la vez anterior al sentido para que la constitución sea efectiva y, posterior al sentido para que este se nos dé en una evidencia a priori $\mathrm{u}$ originaria ${ }^{39}$. Aun cuando no se proseguirá aquí una reconstrucción mayor de este argumento, interesa destacar que Derrida señaló, con ello, la imposibilidad de una determinación real de un comienzo absoluto ${ }^{40}$. La complicación entre génesis y estructura, o entre lo empírico y lo trascendental, terminará por favorecer en Derrida un pensamiento otro que desde su retraso avanza hacia su origen, pero que, al mismo tiempo, anuncia la imposibilidad de su proyecto: este sería el pre-texto a partir del cual la materialidad inscribe en los márgenes de la fenomenología aquella "fuerza inaugural del origen» que solicita "trazar el camino hacia la producción de un nuevo origen ${ }^{41}$. A fin de cuentas, Derrida habría seguido a Husserl en torno a la importancia de la síntesis a priori, sin embargo, se habría separado de él toda vez que este, al quedar dialécticamente aprisionado en el idealismo, no habría tenido el coraje de trazar un pasaje donde lo no llegado retorna al comienzo para inscribir, allí, cada vez la posibilidad material de un nuevo exceso en los comienzos de la filosofía.

Objetando, en consecuencia, la reaparición en Husserl de un idealismo trascendental que potenciaría, como indica Derrida, la presencia de idealidades —esto es, lo eidético, la idea, el sentido o el significado- y con ello el carácter pleno de un origen en sí y para sí, la deconstrucción implicaría reconocer, en la senda de un materialismo ni empírico ni sensible, que «un pensamiento de la huella ya no puede romper con una fenomenología trascendental ni reducirse a ella ${ }^{42}$. Esto significa que sobre la premisa husserliana de «ir a las cosas mismas» Derrida pliega, secretamente, aquella denegada tendencia presocrática que mueve el pensamiento hacia el cosmos. No se logra, por tanto, abandonar el idealismo trascendental tan sólo con alcanzar, como lo pretende Husserl en sus Investigaciones lógicas, un a priori material, así como tampoco se alcanza este horizonte sin fin negando la realidad del mundo fenoménico. En ambos casos, lo otro del pensamiento coexiste e interroga al referente que postula tanto la anterioridad como la trascendentalidad del sentido sobre toda realidad. En consonancia con las lecciones de La voix et le phénomène y como escribe más tarde Derrida en Notas sobre deconstrucción y pragmatismo, es de suma importancia insistir en «la necesidad de formular preguntas trascendentales para no quedar atrapado en la fragilidad de un incompetente discurso empirista y, por

39 DERrida, J., Le problème de la genèse..., op. cit., p. 47.

$40 \quad$ Al respecto ver: Marrati-GuÉnoun, P., La genèse et la trace. Derrida lecteur de Husserl et Heidegger. Dordrecht / Boston / London, Kluwer Academic Publishers, 1998, pp. 7-98.

41 Marrati-GuÉnOn, P., La genèse et la trace... op. cit., pp. $126 \mathrm{~s}$.

42 Derrida, J., De la grammatologie, op. cit., 91 [Trad. cit., p. 81]. 
lo tanto, para evitar el empirismo, el positivismo y el psicologismo, es que resulta interminablemente necesario renovar el cuestionamiento trascendental» ${ }^{43}$.

\section{CUESTIONAMIENTO TRASCENDENTAL, HUELLA Y REINSCRIPCIÓN DE LO SENSIBLE}

Ante la necesidad de renovar interminablemente el cuestionamiento trascendental, cabe multiplicar las preguntas con el fin de bosquejar las coordenadas tanto generales como restringidas del problema sobre el cual se sostiene esta tratativa: ¿implican per se la deconstrucción del logocentrismo y la crítica del idealismo la afirmación de un materialismo no metafísico?, ¿cómo y a partir de qué movimientos este materialismo, en su lucha contra el idealismo, puede no quedar reducido a la presencia sensible ni responder a la intencionalidad de un significado trascendental?, ¿qué quiere decir que la materialidad ya no pertenezca al registro de la sensibilidad?, ¿significa, acaso, que la materialidad sobrevive si y solo sí se convierte en un objeto ideal desapasionado?, ¿es posible un acceso no platónico a la materialidad y, por extensión, una definición no metafísica del materialismo?, ¿puede realmente la materialidad exceder y restarse del dualismo metafísico?, ¿acaso se trata de un materialismo de la ausencia, de lo indefinido, de la alteridad en su radicalidad, de lo suspendido y del espaciamiento?, ¿puede afirmarse una tal posibilidad o está se desvanece en su afirmación?, ¿qué relación existe, en estricto rigor, entre el texto materialista y el pensamiento de la deconstrucción?, ¿puede definir el concepto de materia Jacques Derrida?, ¿puede el materialismo no metafísico surgir de una fuente distinta al texto y la tradición materialista?, ¿Cuáles son, por tanto, las fuentes filosóficas que permiten la emergencia en Derrida de un pensamiento de la materialidad?, ¿hasta dónde la materia realmente puede encarnar la marca de una heterogeneidad radical de la metafísica y no quedar apresada por esta?, ¿irrumpe y frustra la materialidad el carácter inteligible de las proposiciones relativas al fundamento?, ¿abre la materia, en la mutabilidad de sus movimientos, un pensamiento del origen sin origen?, ¿acontece la materia al modo de un accidente que marca, en su devenir, la lógica de lo trascendental y se inscribe en ella?, ¿no está acaso contaminado lo trascendental, como señala Catherine Malabou leyendo a Kant desde una perspectiva derrideana, en un punto por la accidentalidad de los primeros tiempos ${ }^{44}$ ?, ¿tal accidentalidad no genera acaso la posibilidad de una concepción residual de lo trascendental? Y si así fuera, ¿en qué consistiría, por una parte, una génesis sensible y material de lo trascendental y, por otra, un devenir trascendental e inteligible de la materia?

Más que responder a este conjunto de preguntas, y otras siempre por venir, es preciso destacar que cada una de ellas materializa un cuestionamiento

43 Derrida, J., «Notas sobre deconstrucción y pragmatismo» en Mouffe, Ch., Deconstrucción y Pragmatismo. Paidós, Buenos Aires, 1998, p. 159.

${ }_{44} \mathrm{Al}$ respecto ver.: Malabou, C., Avant demain. Épigenèse et rationalité. P.U.F. Paris, 2014. 
trascendental cuya singular finalidad es volver poco pertinente la dicotomía entre lo empírico y, valga la redundancia, lo trascendental $-\mathrm{o}$, lo material y lo ideal, lo sensible y lo inteligible, etc. En consecuencia, lo que queda marcado al interior de estas preguntas es el constante reenvío de un término a su otro: es gracias a esta operación, cuya fuerza diferencial cuestiona radicalmente aquellas estructuras a partir de las cuales se determina tanto la plenitud inteligible como la sensible, que Derrida inscribe lo otro en lo uno y logra desfigurar sus relaciones intrínsecas. Es más aún, dicha inscripción impide, por tanto, que se puedan distinguir claramente entre sí las distintas variaciones de los registros empíricos y trascendentales. La pretendida pureza de la distinción queda absolutamente arruinada por los efectos de una «contaminación diferencial $»^{45}$ que, a fin de cuentas, hace posible una serie indeterminada de entrelazamientos. En este contexto, la desfiguración de las dicotomías es el mecanismo que permite la irreductible supervivencia de fragmentos empíricos bajo lo trascendental. Inversa y suplementariamente, subyace lo trascendental bajo lo empírico. En consecuencia, se observa en función de esta doble banda una fragilidad compartida que impide la totalización de un extremo sobre el otro y promueve así su respectiva contaminación. Esta lógica diferencial, que por cierto atraviesa cada texto que lee y sobre los cuales escribe Derrida, no hace sino corromper la pureza de todo enunciado para instalarse en ellos y diseminarse. De ahí que frente al conjunto de preguntas antes enunciadas no haya que adelantar respuesta alguna, sino sólo hace falta precipitar, en el sentido químico de esta última palabra, en la escritura las huellas de su materialidad. En tal sentido, aunque las marcas que figuran en el plexo de estas preguntas terminan por borrarse, antes «realizan un desmantelamiento que muestra una ausencia en la plenitud de la materia ${ }^{46}$. Esta ausencia, a diferencia de lo que pensaban los atomistas griegos, alude a la posibilidad cierta de un vacío interno del átomo y, por ende, supone la divisibilidad infinita de este sin que de ello resulte su completa desintegración ${ }^{47}$. Es decir, en la escritura, aquel «lugar de tránsito de las huellas y de los otros» ${ }^{48}$, la contaminación pone de manifiesto aquellos restos resultantes del proceso de fragmentación y disgregación, permitiendo así, a contracorriente de las perspectivas idealistas, que no haya pérdida sino exceso de materia.

45 Derrida, J., Fuerza de ley. Trotta Editorial, Madrid, 2008, p. 98.

46 Martin, J.-C., Derrida. Un démantèlement de l'Occident. Max Milo Éditions, Paris, 2013, p. 118.

${ }_{47}$ Es importante subrayar que la interpretación que se hace aquí de esta ausencia va a contracorriente de lo que explícitamente señalaban Leucipo, Demócrito y Epicuro, pues, tal y como lo destaca Simplicio en In de caelo, «estos decían que los principios, a los que consideraban también átomos indivisibles e inalterables por ser sólidos y estar libres de vacío, eran en infinitos en número, ya que afirmaban que la división se produce debido al vacío existente en los cuerpos» [Citado en Megino, C., «El origen de la idea de vacío en Grecia». Éndoxa: Series Filosóficas, n. 16, 2002, p. 330]. Hoy, no obstante, con el desarrollo de la física y la mecánica cuántica se sabe que los átomos si son divisibles.

48 Cragnolini, M. B., «Adieu, Adieu, remember me. Derrida, la escritura y la muerte» en Derrida, un pensador del resto, Ediciones La Cebra, Lanús, p. 44. 
Desde esta perspectiva, puede afirmarse entonces que cuanto más la materia se divide en pequeños elementos, más se multiplican los restos en el vacío. Ahora bien, habría que añadir respecto de dicha premisa, que el aumento exponencial de restos no desliga, sin embargo, los elementos que contaminan la estructura. Estos elementos, tal y como sucede con lo trascendental y lo empírico o con la idea y la materia, se mantienen entrelazados, como destaca Derrida en Glas y en La verdad en pintura, por lazos estrictos. Lo empírico, siguiendo el hilo esbozado, se inscribe y atraviesa constantemente lo trascendental cuestionando, así, su carácter inmaculado, pero asimismo lo realiza con la finalidad de preservar eso que ha sido contaminado. Es, por tanto, mediante este encadenamiento o entrelazamiento que se resguarda, "sobre la superficie externa y bajo la superficie interna (y viceversa...) ${ }^{49}$, el paso de un extremo a otro sin que ello suponga una lógica oposicional entre el todo y los elementos particulares. Lo que asegura, en cambio, el paso y la reunión es, como señala Derrida, una ley de estrictura que, habría que agregar, reedita novedosa y diferencialmente la antigua ley del movimiento de los presocráticos ${ }^{50}$.

Al igual que la noción de clinamen, la estrictura considera, tal y como fuera señalado por Demócrito, que el vacío no es la causa sino la condición sine qua non del movimiento. Se puede sugerir, sin alejarse del cuestionamiento trascendental propuesto por Derrida, que la emergencia y multiplicación exponencial de restos que acontecen en el vacío, al interrumpir la pureza de lo trascendental, arrojan, vuelven sensible e inscriben sobre el reverso del pensamiento idealista las marcas empíricas del carácter diferencial. El ritmo, en tanto «fuerza de inscripción de un espaciamiento ${ }^{51}$, no sólo marca, entreabre y divide la materia multiplicándola, sino también guarda las huellas de esta división al subvertir los límites de la idea. En otras palabras, en cada una de las $n$ dimensiones que Demócrito considera, al menos de forma abstracta, para la constitución del llamado gran vacío [méga kénon] se inscriben restos que, oscilando de fragmento en fragmento, no pueden sino trenzarse [sumplochai] con las trayectorias de

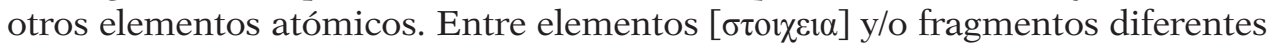
no hay nunca una división ni una distancia realmente absoluta, pues, como en

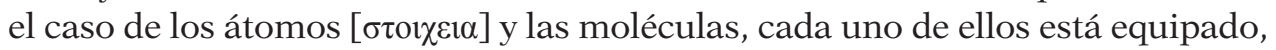
para decirlo en términos físicos, de un conjunto de ganchos o hembrillas que, mediante un encadenamiento por constricción, permiten desencadenar sobre sí un pliegue que se tuerce sobre su otro. El trenzado desdibuja, por tanto, la imberbe lógica del adentro y el afuera al estrangular, pero sin cortar ni separar jamás lo empírico de lo trascendental, eso que en Derrida resta encadenado.

49 Derrida, J.,. La vérité en peinture. Flammarion, Paris, 1978, p. 341[Trad. González, María \& Scavino, Dardo. La verdad en pintura. Paidós, Buenos Aires, 2005, p. 313].

50 Sobre este punto habría que explayarse, sin embargo, en este artículo tan sólo pretendemos circunscribir y adelantar la existencia de un pensamiento de la materialidad en Derrida. En un trabajo en proceso se elabora en detalle la relación entre el pensamiento de J. Derrida y el atomismo. Acá nos limitamos, por ende, tan sólo a presentar las vías de acceso a la cuestión.

51 DerridA, J., «Désistance» en Psyché..., op. cit., p. 628. 
De modo análogo, si los átomos trenzan ilimitadamente sus trayectorias, no ha de extrañarnos que, como ya lo había señalado Demócrito, se pueda escribir con una cantidad limitada de letras un número ilimitado de tragedias ${ }^{52}$, lo que, sin embargo, no significa, como es pretendido por Lacan en La instancia de la letra en el inconsciente..., la indivisibilidad de esta última. Si para Heráclito, como indican Kirk, Raven y Schofield en su famosa historia crítica sobre los filósofos presocráticos, «el acto de escribir combina lo recto en toda la línea con lo oblicuo en la forma de cada letra ${ }^{53}$, esto ya implica la insistencia, en dicha instancia, de una contaminación trascendental. Lo oblicuo, ante todo lo recto, o la letra como inscripción sensible que conlleva la instancia de la huella instituida $^{54}$, facilita que el movimiento, el ritmo y la cadencia de lo empírico lleguen a dividir, contaminar y torcer, en la escritura, la dimensión estática y rígida de lo trascendental. Por tanto, la divisibilidad del átomo, así como la divisibilidad de la letra, constituyen «la primera condición de la deconstrucción» ${ }^{55}$.

\section{Del Átomo a LA DIVISIBILIDAD DE LA LETRA}

El punto de vista con el que Derrida defiende la divisibilidad del átomo y la letra constituye, aunque en ninguno de sus textos ha sido expuesto como tal, el origen adverso de la indivisibilidad de la materia. Si antiguamente el átomo fue considerado como una partícula indivisible, lo que conllevaba la división limitada de la substancia, entonces el materialismo, por defecto, se configuró históricamente al modo de una autoconservación de sí incapaz de superar el determinismo de su núcleo, aun cuando reconocía que el mundo material no podía sino encontrarse en un constante cambio. Objetando, en parte, la herencia parménidea sobre la cual descansa el principio de permanencia del átomo y, por otra, subrayando con Heráclito el cambio como condición que hace posible el movimiento en el vacío, Derrida interpreta los átomos como trazas de escritura. En su interior marca el lugar de una escisión y, por tanto, el vacío no es sólo

52 Leibniz en su juventud, a propósito de una relación entre letra y átomo, sostuvo siguiendo algunos presupuestos de Pierre Gassendi que «con variado orden, dice Epicuro, y posición, los átomos, así como las letras, aunque sean pocas, de un variado colocadas, hacen innumerables palabras»; Cf. LeIBnIz, G., Disertación acerca del arte combinatorio (Santiago de Chile: CIP Pontificia Universidad Católica de Chile; 1992), p. 91. Esto, al menos tentativamente, permite afirmar, como lo hacían los presocráticos, que el átomo es a la realidad y la naturaleza lo que la letra es al pensamiento y al espíritu.

53 Kirk, G. S.; Raven, J. E. y Schofield, M., Los filósofos presocráticos. Historia critica con selección de textos. Parte I. Editorial Gredos, 1987, p. 220.

54 Derrida, J., De la grammatologie. Les Éditions de Minuit, Paris, 1967.

55 Derrida, J., «La sociedad del pos-consumo y el papel de los intelectuales. Entrevista con Kojin Karatani y Akira Asada». En: Revista Pliegos de Yuste, n³, mayo, 2005, p. 45. Cabe destacar que esta entrevista, en la que se alude como en otras ocasiones a la relación entre el pensamiento de la deconstrucción y el atomismo, se realizó en Japón el 25 de mayo de 1984, es decir, a dos años de la publicación de Mes chances y dos años antes de la entrevista que se ha citado al inicio de este artículo, a saber, Del materialismo no dialéctico. 
el espacio externo donde el átomo se mueve, sino que es también el espacio interno que inscribe la dimensión de su propagación como infinita división de sí. La diseminación del átomo es, en consecuencia, la inseminación de sus partes disueltas en el sistema. De este proceso doble, en el que unos restos se diseminan al inseminarse como las contrapruebas de la escritura derrideana, surge una multiplicidad de pequeños objetos que exceden sus propios límites. Asunto este que no habría que tomar a la ligera, pues, es en virtud de estas circunstancias que esos pequeños excedentes llegan a incorporarse en la textualidad y el pensamiento de J. Derrida como los signos escritos de la diferencia, es decir, como aquello carente de identidad y significación: «la letra, por ejemplo, el stoikheion, el último elemento, forma parte de la lexis, pero no tiene ningún sentido en sí misma $»^{56}$. Esta ausencia de sentido, sin embargo, posibilita múltiples y diferentes trayectos que se mueven, tal y como queda señalado en La différance ${ }^{57}$, en el curso de una escritura en y sobre la escritura. La letra $a$, con la que se altera la diferencia [différence], aun cuando no tenga significación alguna por si sola constituye ese peligroso suplemento que no habla jamás de sí, pero cuya inclinación hacia lo otro excluido es indispensable para su propia dislocación. Este injerto textual, si se lee esto de otro modo, permite la producción de un exceso indecidible en el que se reinscriben los átomos en sus desvíos.

Epicuro, completando la teoría de Leucipo y Demócrito, es rescatado en este contexto por Derrida en varios textos, pero de forma absolutamente discontinua, precisamente porque ve en su concepto de clinamen una crítica a la rigidez y un intento de mellar el determinismo. El movimiento imprevisto y azaroso de los átomos cuestiona, en definitiva, la concepción del ser como presencia. Desde esta perspectiva, los átomos son, como se decía, huellas o trazos de una escritura que no responden a la idealidad del significante, pues si lo hicieran quedarían retenidos en la dicotomía presencia/ausencia, cuando, en estricto rigor, se encargan de socavar, dislocar y agrietar su estructura. Ante la indivisibilidad del átomo y la letra (propuesta por los antiguos atomistas), ante el encadenamiento posterior del significante y el significado (propuesto por Saussure, Lacan y los estructuralistas en general) o ante la supuesta pureza de la totalidad (propuesta por Hegel) y frente a «las idealidades encadenadas en la historia empírica» (Husserl), Derrida, siguiendo a Joyce, promoverá «la mayor potencia de las intenciones escondidas, acumuladas y entremezcladas en el alma de cada átomo lingüístico, de cada vocablo, de cada palabra, de cada proposición simple» ${ }^{58}$. Lo que subyace o se incorpora al interior del átomo, la

56 DERRIDA, J., «La mythologie blanche. La métaphore dans le texte philosophique» en Marges de la philosophie. Les Éditions de Minuit, Paris, 1972, p. 281 [Trad. González, Carmen. Márgenes de la filosofía. Ediciones Cátedra, 1994, p. 275].

57 Derrida, J., «La différance» en Marges de philosophie, op. cit., pp. 1-30 [Trad. Cit., pp. 37-62].

58 DERRIDA, J., Introduction à L'Origine sur la géométrie. P.U.F, París, 1962, p. 104. [Traducción Cohen, Diana. Introducción a El origen de la geometría de Husserl, Buenos Aires, Manantial, 2000, p. 102]. 
letra e incluso al interior de la idealidad sería, ni más ni menos, que el irreductible movimiento de la escritura ${ }^{59}$.

Es en esta dirección que Derrida en De la gramatología, al volver sus pasos sobre El origen de la geometría, podrá señalar que la objetividad ideal para constituirse «debe pasar [necesariamente] por el significante escrito» ${ }^{60}$. La escritura conservaría en efecto «no sólo la opacidad en la idealidad del objeto, sino que permitiría», en los límites de las nociones de inscripción y huella, «la liberación de esta idealidad ${ }^{61}$. En este punto, nada impide señalar que la materialidad acontece como una sombra que prefiguraría la huella de un presente ausente. Tal ausencia de referencia [Skiagrafía ${ }^{62}$, acaecida producto de la fisión de cada átomo de escritura, deconstruye la jerarquía entre lo sensible y lo inteligible, entre lo material y lo ideal o, como se señalaba con anterioridad, entre lo empírico y lo trascendental. Pues, es bajo el ritmo de «la divisibilidad de la letra» ${ }^{63}$ que se encuentra, habitando el corpus de lo escrito, el soporte y la afirmación de aquello que no puede ser reproducido. A pesar de sostener sus secretas condiciones de posibilidad, lo que se escondería en los bajos fondos de la deconstrucción es también lo que se despliega gracias a ella. Ese algo oscuro [ádêlos] que se despliega, pero que al mismo tiempo se mantiene en secreto, es precisamente aquella magnitud mínima que existiendo al interior del átomo permite su divisibilidad ${ }^{64}$.

En sus lecturas, Derrida constantemente da a leer, mediante la inscripción sensible de una letra que lo transforma todo, ese algo oscuro que vuelve imposible la indivisibilidad de la sustancia. Deja que los entresijos acontezcan donde no se los esperaba y, con ello, abre la textualidad metafísica e idealista injertando en ella otra escritura: en la disyunción de la metafísica, ahí donde lo empírico y lo trascendental a pesar de su distancia mantienen su ligazón, se genera no sólo el elemento atómico sino también su división: así como el átomo se insemina en el vacío, la letra se injerta en el texto como un residuo del pensar a partir del cual no deja nunca de contaminar la idealidad del sentido.

59 «La encamación lingüística y la constitución del espacio escritural suponen, pues, un "encadenamiento" cada vez más estrecho de la idealidad en la realidad, a través de una serie de mediaciones cada vez menos ideales y en la unidad sintética de una mención. Esta síntesis intencional es un movimiento incesante de ida y vuelta, que trabaja para encadenar la idealidad del sentido y para liberar la realidad del signo, estando cada una de estas dos operaciones imbuida del sentido de la otra, que ya se anuncia o todavía se conserva en ella. Por el lenguaje, la idealidad del sentido se libera, pues, en el trabajo mismo de su "encadenamiento"». Ibid., p. 87 [trad. cit., p. 87].

60 DerridA, J., "De la grammatologie comme science positive» en De la grammatologie, op. cit., p. 134 [trad. cit., p. 119].

61 Ibidem.

62 Von Amelunxen, H. \& Wetzel, M., «La fotografía, copia, archivo, firma. Entrevista con Jacques Derrida» en Minerva: Revista del Círculo de Bellas Artes, N. ${ }^{\text {7, }}$ 2008, p. 81.

63 Derrida, J., Ulysse gramophone. Deux mots pour Joyce. Éditions Galilée, Paris, 1987, pp. 100-101.

64 Cabe destacar, como lo ha hecho Pascal Graff, que para Epicuro esta magnitud mínima es la que marca, a fin de cuentas, el límite de la división. GrafF, P., La «déviation» dans l'épicurisme. Entre hasard et nécessité. Éditions Aletheis, Paris, 2014, p. 21. 
El carácter material de la letra no tiene que ver, entonces, con su estructura anatómica y literal: en su dejar marcas, ella no es otra cosa sino el soporte de la inscripción en su indecidibilidad. A diferencia de lo planteado por Lacan en un texto originalmente publicado en 1957, la letra no designa aquí el «apoyo material que el discurso concreto toma prestado del lenguaje» ${ }^{65}$, es decir, no es una forma abstracta sobre la cual se yuxtapone un contenido empírico cuya finalidad es garantizar la preinscripción del sujeto [sujet en francés también significa «materia» en cuanto tema o asunto]. Ahora bien, Derrida a pesar de todas sus diferencias con Lacan sostiene, al igual que este último, que «la letra es materia, pero no sustancia ${ }^{66}$. Sin embargo, lo que configura la infranqueable distancia entre ellos respecto de este asunto dice relación con la condición de indivisibilidad con la que Lacan defiende la materialidad del significante y que, por su parte, Derrida objeta por considerarla una expresión que eleva la indestructibilidad de la letra a la idealidad del sentido ${ }^{67}$.

La idealización - ya sea de la letra, el átomo o de una obra de arte cualquiera- supone, tal y como indicaba Derrida en una conferencia del 1 de marzo de $2002^{68}$, la prohibición de separar el subyectil de la obra, lo que equivale, grosso modo, a mantener la indisociabilidad del significante con el significado. Ante esto cabe preguntar: ¿Cómo podría haber obra de arte sin que exista debajo de ella un soporte? ¿Cómo un significado podría desplegarse en ausencia de significante? $\mathrm{O}$, en términos más abstractos e insistiendo con lo ya esbozado: ¿Cómo lo trascendental, lo inteligible, lo ideal y/o lo puro podría prescindir para su establecimiento de lo empírico, lo sensible, lo material y/o ese algo oscuro que lo contamina todo? En estricto rigor, no hay modo de impedir que este desgarramiento entre lo uno y lo otro pueda darse, pero este no puede darse en términos absoluto, pues, como sugiere Derrida en Artes de lo visible, «lo inseparable mismo se divide o se multiplica ${ }^{69}$. Ciertamente, podría afirmarse que en el acto de la división lo trascendental llega a prescindir de lo empírico, así como la idea lo haría de la materia e inversamente, sin embargo, en el instante mismo en que un elemento se priva de su opuesto, lo evita o silencia, ese otro que es negado se convierte en un desecho al que no se puede renunciar, pues lo escindido es siempre una parte del todo que se mantiene a cierta distancia de sí. Así como la obra de arte «no tolera la separación» entre, "por una parte, la sustancia del soporte

65 LaCAN, J., «L'instance de la lettre dans l'inconscient ou la raison depuis Freud» en Ecrits. Le Seuil, Paris, 1966, p. 495.

66 Lacoue-Labarthe, P. \& Nancy, J.-L., Le titre de la lettre. Une lecture de Lacan. Éditions Galilée, Paris, 1973, p. 46.

67 En torno a esta diferencia ver: DERRIDA, J., «Le facteur de la vérité» en La carte postale. Flammarion, Paris, 1980, pp. 492-494 [Trad. Segovia, Tomás. «El cartero de la verdad» en $L a$ tarjeta postal. Siglo XXI editores, México, ${ }^{2} 2001$, pp. 436-437]. Una lectura complementaria, atenta a ambos autores, se encuentra en Alfandary, I., Derrida-Lacan. L'écriture entre psychanalyse et déconstruction. Hermann éditeurs, Paris, 2016.

68 DERRIDA, J., "Debajo de la pintura, de la escritura y del dibujo: soporte, sujeto, supuesto y suplicio» en Artes de lo visible (1979-2004). Ellago ediciones, Castellón, 2013, pp. 247-262.

69 Ibid., p. 255. 
o del subyectil (...) y, por otra parte, el encima de la forma ${ }^{70}$, Derrida, para usar las palabras que acabamos de citar, «no tolera la separación» de lo trascendental y lo empírico, —u otra separación de esta misma índole-, pero, justamente por ello, exige su división para que cada uno de los polos corrobore su paradójica función al interior del sistema. A esta inevitable distancia, abierta entre ambos polos de una oposición, Derrida suele llamarle, al menos desde 1966 en adelante, espaciamiento. Ahora bien, lo que tiene lugar en el entre es precisamente aquello que puede mantener la unidad en la separación sin que por ello deje de haber división: es decir, de la división entre la sustancia del soporte y el encima de la forma (superficie) surge y se dibuja, a partir de una «operación que a la vez introduce la confusión entre los contrarios y tiene lugar entre estos», un «medio como elemento que envuelve a los dos términos a la vez: manteniéndose el medio entre ellos» ${ }^{71}$. En consecuencia, tanto la operación deconstructiva como el entredós que ha surgido de ella, dicho sumariamente, no niegan la existencia de bordes y márgenes entre lo trascendental y lo empírico - y viceversa—, sino que en el interregnum de la metafísica suspenden la pretendida pureza y determinación exacta de estos límites.

Esta suspensión en cuanto tal de los límites, que es también un trastocamiento y una exapropiación del orden jerarquizante, le permite a Derrida desmembrar, una y otra vez, aquellas demarcaciones territoriales que impiden reafirmar, por una cuestión de forma, la singularidad del trazo en sus respectivos despuntes. La divisibilidad del átomo, la letra y la obra de arte, así como la de cualquier otra cosa existente, implica en tanto afirmación de lo minúsculo una multiplicación de su volatilidad. En el parágrafo 63 de sus Cartas y sentencias Epicuro señala, a propósito de la materialidad del alma, que esta se define como «un cuerpo formado por finas partículas diseminadas a través de todo un corpus ${ }^{72}$, razón por la cual no puede ser ella, como lo destaca Jean Salem, de ninguna manera incorpórea ${ }^{73}$. Ahora bien, desde el punto de vista que veníamos trabajando respecto de la divisibilidad del átomo, habría que agregar que Derrida, sin contradicción alguna con esta sentencia, apela tanto a la literalidad como a la inmaterialización de la materia ${ }^{74}$. Por tanto, la diseminación de aquellas finas partículas a partir de las cuales se escribe un cuerpo cualquiera - se trate de un cuerpo material o inmaterial (como en el caso del alma, el espíritu y los espectros) - son también las que horadan la superficie y los límites con que la representación pretende reapropiarse e inmovilizar el movimiento

70 Ibidem.

71 Derrida, J., «La double séance» en La dissémination. Éditions du Seuil, Paris, 1972, p. 240 [Trad. Arancibia, José. Editorial Fundamentos, Madrid, ${ }^{7} 1997$, p. 321]. Traducción levemente modificada con fines estilísticos (básicamente hemos evitado repetir innecesariamente algunas palabras sin que dicha ausencia altere el sentido de la frase original).

72 Conche, M., Épicure. Lettres et maximes. Éditions P.U.F, Paris, 1987, p. 113.

73 Salem, J., Démocrite, Épicure, Lucrèce. La vérité du minuscule. Éditions Les Belles Lettres, Paris, 2014.

74 Derrida, J., «To Unsense the Subjectil» en Thévenin, P. \& Derrida, J., The secret art of Antonin Artaud. The МГГ Press, Massachusetts, 1998. 
de la escritura que hace posible, en distintos grados, la densidad e intensidad de los cuerpos. Es decir, estas finas partículas, en su diseminación, producen ellas mismas los poros que utilizan para atravesar la forma de lo constituido y consentir así no sólo la división [tomus] del receptáculo inerte sino también la división del átomo [atomus]. Pues, en tal sentido, hay que señalar que el átomo - lo supuestamente in-divisible- es también un corpus y, debido a esto, como cualquier otro cuerpo está, a su vez, atravesado por lo otro de sí.

Esta última proposición, aunque lo parezca, no avanza en ningún sentido contra la tradición materialista inaugurada por Demócrito y posteriormente retomada por Epicuro y otros: si el átomo es como una letra, si la existencia es

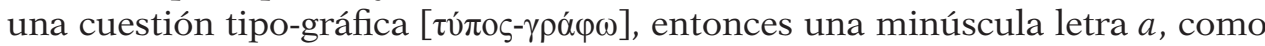
la promovida por Derrida en la différance, hace del $a$-tomo «a», esto es, hace de la negación representada por el prefijo (a) en el caso del átomo o en su calidad de interfijo en la différance no una partícula de negación sino la convierte en una diferencia que opera en la misma división. La «a» ocupa en ambos casos un lugar sin ocuparlo, acontece como una suerte de eterno retorno de lo mismo que permite reconsiderar, a cada instante, el estatuto de la materialidad. La división y el movimiento resultante del átomo permiten, tal y como lo coligió Nicolas d'Autrecourt en el siglo XIV, «deducir la negación de la finalidad» ${ }^{75}$, pero a diferencia suya acá no se afirma la indivisibilidad del átomo sino precisamente lo contrario: el movimiento de la división no tiene fin ni finalidad porque, tal y como lo dirá Derrida en To Unsense the Subjectile, «los átomo son literalmente átomos, es decir, como con los atomistas griegos, son figuras y letras $»^{76}$ en tanto bloquean la tendencia formalista. El átomo, en efecto, «es la letra en movimiento [in motion] $\gg^{77}$, es un soporte que se desplaza e insiste en su volatilidad, es una fina partícula que se excede a sí misma, se yecta, y al hacerlo perfora su propia superficie de exhibición. ${ }^{78}$ En suma, en cuanto el átomo se divide en su encuentro con el otro, el otro queda en sí mismo dividido, multiplicando así las finas partículas a partir de las cuales se multiplica la división del átomo en una división que se multiplica en otros átomos. Ahora bien, de esta reacción en cadena o de este efecto multiplicador, se sabe, actualmente, que quedan restos que han sido escindidos de su núcleo, —unos al ser liberados como energía y otros como residuos nucleares-, y que, por ello, no pueden ser (re)capturados.

\section{DE LO YECTO A LO ABYECTO: EL DEVENIR ININTERRUMPIDO DE LA DIVISIÓN}

El hecho de que las partículas elementales —átomos, letras, moléculas, etc.- - no puedan ser del todo contenidas en su estallido es precisamente aquello que permite que estas formen, como el mismísimo Kant reconoció siguiendo a

75 BréHier, É., La philosophie du Moyen Âge. Albin Michel, Paris, 1971, p. 416.

76 Derrida, J., «To Unsense the Subjectile», op. cit., 1986, p. 90.

77 Ibid., p. 100.

78 Ibidem. 
los antiguos atomistas, el origen del mundo a partir y por medio del $\operatorname{caos}^{79}$. Aun cuando Kant defendiera, contra la posición epicúrea del accidental encuentro entre los átomos, una concepción de «la materia atada a ciertas leyes necesarias», debió reconocer que el movimiento era originalmente inherente a la materia. En el caso de Kant, no obstante, lo que posibilitaba dicho movimiento era una inteligencia superior y no, como en la tradición materialista antigua, «un elemento sensible» que, al «constituir el principio de las cosas», ha sido y será «siempre susceptible de ser disociado y destruido»" ${ }^{80}$. Ahora bien, sabemos hoy, gracias a la física de partículas, que ninguna destrucción será total y, por tanto, que de una división atómica siempre quedarán restos que ya figuraban en el átomo incluso antes de su división ${ }^{81}$. La polarización del vacío — descrita y estudiada por la electrodinámica cuántica- señala, por ejemplo, que las partículas, sin interferencia de otras, aparecen y desaparecen sin dejar rastro en el vacío. A propósito de fenómenos como este, G. Hooft ha señalado que «quizás los quarks no sean partículas, sino (...) fantasmas» ${ }^{82}$. Desde este punto de vista, lo que importa destacar es, como ha ocurrido desde Leucipo en adelante, que el vacío es causa del movimiento y que el ser esta siempre desplazándose, en tanto que «el átomo es al mismo tiempo un cuerpo y un inteligible» ${ }^{83}$. El carácter $o$ la condición espectral de la materia parece ser una realidad nueva por pensar, puesto que la determinación dinámica del átomo le permite aparecer y desaparecer en el vacío sin dejar de ser la causa material de su división. Ciertamente, esto implica una diferencia sustancial con respecto a las versiones clásicas en torno al carácter indivisible del átomo. La divisibilidad del átomo permite una sucesión infinita de partículas cada vez más pequeñas, irregulares e infrecuentes que, por lo general, tienden a ser desconsideradas. Como ha señalado Claude Gaudin, «hay un momento donde el pensamiento de lo mínimo tiende a desbordar el concepto de átomo» ${ }^{84}$. Ese momento ha sido tematizado entre otros por Epicuro, Lucrecio y Derrida, pues cada uno de ellos sostiene que lo mínimo puede dividirse al infinito. Del cosmos a las existencias menores, de la materia a los átomos y de estos a los quarks, existe una secuencia que se divide en segmentos cada vez más pequeños y, por ello mismo, se expande hacia un infinito cada vez más imperceptible, como ha sido evidenciado en la geometría fractal de B. Mandelbrot, en el que se revelan nuevas estructuras.

El efecto del devenir iterado de la división acontece de este modo como una inscripción que excede y desborda, tal y como ocurre con la escritura en

79 Cf. Kant. I., «Prefacio» en Historia natural y teoría general del cielo. Editorial Lautaro, Buenos Aires, 1946, pp. 25-39.

80 Salem, J., Démocrite. Grains de poussièrre dans un rayon de soleil. Librairie philosophique J. Vrin, Paris, ${ }^{2} 2002$, p. 41.

81 Cf. Hooft, G., Las partículas elementales. En busca de las estructuras más pequeñas del universo. Editorial Crítica, Barcelona, 2001.

82 Ibid., p. 76.

83 Morel, P.-M., Démocrite et la recherche des causes. Éditions Klincksieck, 1996, p. 58.

84 Gaudin, C., Lucrèce. La lecture des choses. Éditions Encre marine, Paris, 1999, p. 64. 
Derrida, el lugar de su origen. Es decir, al disociarse las partículas elementales de sí mismas y, en consecuencia, al multiplicarse en su división, estas tienden a diseminarse en un rastro sin trazabilidad. En Firma acontecimiento contexto Derrida señalaba, en esta misma línea, pero con respecto a cualquier elemento del lenguaje (marca, signo, etc.), que «esta posibilidad estructural de ser separado del referente o del significado (...) hace de toda marca, aunque sea oral, un grafema en general, es decir, como hemos visto, la restancia no-presente de una marca diferencial apartada de su pretendida "producción" u origen ${ }^{85}$. Como «todo signo, lingüístico o no lingüístico», grafemas y partículas elementales pueden "romper con todo contexto dado" y "de manera absolutamente no saturable» «engendrar al infinito nuevos contextos» ${ }^{86}$. El estallido atómico cumple así una doble función: destruye, pero no aniquila, y centuplica todo lo sólido al tiempo que transforma lo yecto en abyecto.

Arrojados como proyectiles en el cosmos, aquellos restos o remanentes de la división no tienen más chance que devenir realidades en acto. Como creía Empédocles, los restos no existen en otro lugar que no sea en los elementos físicos y en los intersticios que se forman a través de sus yuxtaposiciones. Heredero clandestino de esta posibilidad, Derrida está, no obstante, más interesado en la deconstrucción de un principio que en su constitución, razón por la cual prefiere buscar en la división la yuxtaposición de los elementos que cada partícula de polvo conserva de una multiplicidad que le era anterior. La composición y descomposición de la realidad física opera en él, porque no existe fuera de texto, como la yuxtaposición mutua de pequeñas parcelas (Empédocles) cuya «forma no tiene consistencia orgánica», pero que actúan como condición, y no como consecuencia, de combinaciones ritmadas de lo trascendental con lo empírico. ${ }^{87}$ Más allá de la metafísica lógica de las oposiciones, lo yecto, en el caso de Derrida, es facilitado por lo abyecto, por las variaciones rítmicas de un estallido atómico que resuena por debajo de un pensamiento organizado de modo sistemático. En otras palabras: «es siempre un elemento excluido del sistema el que asegura el espacio de posibilidad del sistema ${ }^{88}$. La existencia de lo raro, lo bastardo, lo monstruoso, entre otras cuestiones, pervive como repetición sintomática que impiden el cierre dogmático con el que se suele constituir la lógica del concepto. Lo abyecto desborda así tanto trascendental como empíricamente el orden discursivo, pues lo desintegra mediante un «ritmo entrecortado» que

85 Derrida, J., «Signature événement contexte» en Marges de la philosophie. Les Éditions du Minuit, Paris, 1972, p. 378 [Trad. Pávez, Javier. «Firma acontecimiento contexto» en Derrida, J., Limited Inc, Pólvora editorial, Santiago de Chile, 2018, p. 31; el texto citado fue originalmente traducido por Carmen González Marín y publicado en 2004 en Márgenes de la filosofía por la editorial madrileña Catedra (p. 359). Hemos preferido citar la traducción de Pávez por ser, a juicio de este articulista, más ajustada al pensamiento de la restancia que Derrida pone en juego en ese y otros textos.

86 Ibid., 35 [Por razones de estilo hemos invertido el orden original de la frase].

$87 \mathrm{Al}$ respecto ver. Sauvanet, P., Le rythme grec. D'Héraclite à Aristote. Presses Universitaires de France, Paris, 1999.

88 DerridA, J.,. Glas. Éditions Galilée, Paris, 1974, p. 183 a. 
suspende y produce el «flujo de lo uno en lo otro» ${ }^{89}$. Es, en efecto, en el contexto de la caída permanente y de la inclinación azarosa de unos átomos con otros que el cosmos presocrático adquiere en Derrida la extensión de una galáctica ${ }^{90}$. Sólo allí, en ese espacio en expansión constante, pueden estos proyectiles escriturar un pensamiento de la materialidad.

En suma: el movimiento de los átomos en el vacío, su ininterrumpida división y por ende su constante multiplicación, es homologable en Derrida a la resistencia ejercida por lo que resta en el proceso mismo de totalización. Es decir, lo que resta no es, como ha señalado acertadamente Mónica Cragnolini, lo que queda después de un ejercicio de desmantelamiento crítico $^{91}$, pues, lo que resta, como escribe Derrida en Glas, no «es el residuo de una operación (sustracción o división), un desperdicio, un desecho que tumba o permanece. El resto, aquí, provocaría más bien la operación $»^{92}$. Al igual que los átomos, el resto «no sería: ni presencia, ni sustancia, ni esencia ${ }^{93}$ o, como señala Derrida en un injerto localizado en la página 7a de Glas, el resto trata invariablemente de lo «que resta por pensar». En consecuencia, que la deconstrucción pueda ser palpada en su declinación hacia una textualidad materialista no pasa tan sólo por reabrir el debate metafísico entre corrientes idealistas y materialistas, sino que de un modo más relevante pasa por marcar lo impensado del pensamiento y, con ello, parasitar la lógica inmaculada e ideal de la filosofía como sistema. En el caso de J. Derrida, como hemos señalado, las letras como los átomos en su diseminación, cuando esta última es aleatoria, se arrojan sobre un campo en el que la colisión de unos contra otros ya no se puede detener. Esta variante respecto de los enunciados clásicos del pensamiento presocrático libera lo abyecto que nunca ha dejado de habitar el cosmos. De ahí que un pensamiento de la materialidad en Derrida sólo «se daría a leer por citas (necesariamente truncadas ...)», mutiladas y reconfiguradas, esto es, bajo la égida de una lectura de fragmentos no dialectizables. De ahí que un pensamiento derrideano de la materialidad sea un modo de inocular lo abyecto e invertir aquella «tradición filosófica [que] siempre ha considerado al materialismo como un modo de pensamiento inferior y degradado ${ }^{94}$. Si, como lo ha constatado Jean-Claude Bour-din, «las palabras "materialistas" y "materialismo" son casi siempre invocadas de manera peyorativa e insultante» ${ }^{95}$ o, como ha señalado François Dagognet, si en el camino del idealismo «la materia» es «tenida sin duda por insignificante, pobre

$89 \quad$ Ibid., p. 166 a.

90 Cf. Prière d'insérer en DeRrida, J., Glas.

91 Cragnolini, M., «El resto, entre Nietzsche y Derrida» en Derrida, un pensador del resto. Ediciones La Cebra, Lanús, 2012, pp. 137-156.

92 DerridA, J., Glas. op. cit., p. 253a.

93 Ibidem.

94 Charbonnat, P., Histoire des philosophie matérialistes. Éditions Kimé, Paris, ${ }^{22013,}$ p. 35 .

95 Bourdin, J.-C. (Dir). Les matérialismes philosophiques. Éditions Kimé, Paris, 1997, p. 10 . 
e irrisoria. [e incluso sií es] considerada lo vil y lo impuro» ${ }^{96}$, entonces, esta será considerada e inoculada por Derrida en su escritura como la fuerza que permite movilizar la insurrección de una nueva posición en filosofía. Una posición que implica abandonar el camino recto de las interpretaciones tradicionales para dejarse llevar por la desviación, la aleatoriedad, lo oblicuo, lo aporético, pero más importante y menos explorado, por un pensamiento cuasi-trascendental de la materialidad que permite desontologizar la materia.

\section{BiBLIOGRAFÍA}

Alfandary, I. (2016). Derrida-Lacan. L'écriture entre psychanalyse et déconstruction. Paris: Hermann éditeurs.

Althusser, L. (1993). «L'unique tradition matérialiste», Revue Ligne. Paris: Éditions Hazan.

Asensi, M. (2006), Los años salvajes de la teoría. Philippe Sollers, Tel Quel y la génesis del pensamiento post-estructural francés. Valencia: Tirant lo Blanch.

Bandhar, B. and J. Goldberg-Hiller (ed) (2015). Plastic Materialities: Politics, Legality, and Metamorphosis in the Work of Catherine Malabou. Durham: Duke University Press.

Barad, K. (2007). Meeting the Universe Halfway: Quantum Physics and the Entanglement of Matter and Meaning. USA: Duke University Press Durham.

Barberi, P.; Kristeva, J. et. al. (1972). Colloque de Cluny: Littérature et ideologie, La nouvelle critique, Paris 1970 [Trad. Socorro, Thomas. Literatura e ideologías. Madrid: Alberto Corazón.

Billi, N. «Materialidad y agujeros sin espíritu: Artaud entre Blanchot y Derrida». Aisthesis [online]. 2017, n.61 [citado 2018-09-10], pp. 9-23. ISSN 0718-7181. Disponible en: http://dx.doi.org/10.7764/aisth.61.1.

-. (2014). «La cosa escrita. Materialismo y lenguaje en Maurice Blanchot». Revista Actuel Marx / Intervenciones, $\mathrm{N}^{\circ}$ 16, Primer semestre, 2014, pp. 69-89.

Bourdin, J.-C. (Dir) (1997).. Les matérialismes philosophiques. Paris: Éditions Kimé.

Bréhier, É. (1971). La philosophie du Moyen Âge. Paris: Albin Michel.

Conche, M. (1987). Épicure. Lettres et maximes. Paris: Éditions P.U.F.

Colebrooke, Cl. (2011). "Matter without Bodies». Derrida Today 4, no. 1.

Cragnolini, M. B. (2012). Derrida, un pensador del resto, Lanús: Ediciones La Cebra.

Charbonnat, P. (2013). Histoire des philosophie matérialistes. Paris: Éditions Kimé.

Dagognet, F. (1997). Des détritus, des déchets, de l'abject. Une philosophie écologique. Le

Plessis-Robinson: Institut Synthélabo pour le progrès de la connaissance.

Derrida, J. (1962). Introduction à l`Origine sur la géométrie. Paris: P.U.F, [Traducción

Cohen, Diana. Introducción a El origen de la geometría de Husserl, Buenos Aires, Manantial, 2000].

—. (1967). De la grammatologie. Paris: Les Éditions de Minuit.

—. (1972). Positions. Paris: Les Éditions du Minuit.

—. (1972). Marges de la philosophie. Paris: Les Éditions du Minuit.

96 Dagognet, F., Des détritus, des déchets, de l'abject. Une philosophie écologique. Le Plessis-Robinson: Institut Synthélabo pour le progrès de la connaissance, 1997, p. 27. 
—. (1972). La dissémination. Paris: Éditions du Seuil. [Traducción Arancibia, José María. La diseminación. Editorial Fundamentos, 32007]

—. (1974).Glas. Paris: Éditions Galilée.

-. (1978). La vérité en peinture. Paris: Flammarion. [Trad. González, María \& Scavino, Dardo. La verdad en pintura. Paidós, Buenos Aires, 2005].

-. (1980). La carte postale. Paris: Flammarion. [Trad. Segovia, Tomás La tarjeta postal. Siglo XXI editores, México, ${ }^{2} 2001$.

-. (1986). Del materialismo no dialéctico. Entrevista con Kadhim Jihad. Diario 16 Culturas, $\mathrm{n}^{\circ} 69, \mathrm{IV}$.

-. (1987). Ulysse gramophone. Deux mots pour Joyce. Paris: Éditions Galilée.

-. (1987-1988). Psyché. L'invention de l'autre. Paris: Éditions Galilée. [Trad. Psyché. Invención del otro. Adrogué, Ediciones La Cebra; 2016].

-. (1990). Le problème de la genèse dans la philosophie de Husserl. Paris: P.U.F.

—. (1992). «Entre crochets (I)» y «Ja, ou le faux-bond» en Points de suspension. Entretiens. Paris: Éditions Galilée.

—. (1992). «Nous autres grecs» en Cassin, Barbara. Nos grecs et leurs modernes. Les stratégies contemporaine d'appropiation de l'antiquité. Paris: Éditions du Seuil.

-. (1993). Khôra. Paris: Éditions Galilée. [Traducción Pons, Horacio. Khôra. Buenos Aires, Amorrortu, 2011].

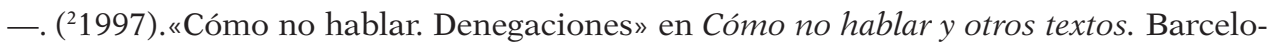
na: Proyecto a ediciones.

-. (1998). «To Unsense the Subjectil» en Thévenin, Paul \& Derrida, Jacques. The secret art of Antonin Artaud. Massachusetts: The МГГ Press,.

—. (1998). "Notas sobre deconstrucción y pragmatismo» en Mouffe, Chantal. Deconstrucción y Pragmatismo. Buenos Aires: Paidós.

—. (1999). «En el límite de la traducción» en No escribo sin luz artificial. Valladolid: Cuatro Ediciones.

-. (2005). La sociedad del pos-consumo y el papel de los intelectuales. Entrevista con Kojin Karatani y Akira Asada. Revista Pliegos de Yuste, N³, mayo.

-. (2008). Fuerza de ley. Madrid: Trotta Editorial.

-. (2013). Artes de lo visible (1979-2004). Castellón: Ellago ediciones.

-. (2018). Limited Inc. Santiago de Chile: Pólvora editorial.

Derrida, J. y Ferraris, M. (2009). El gusto del secreto. Buenos Aires: Amorrortu.

Durán, C. (2018). La soltura del cuerpo. Indiferencias de la diferencia en Catherine Malabou. Chile: Ediciones Metales Pesados.

Gasché, R. (1986). «Literature or Philosophy?» en The Tain of the Mirror. Derrida and the Philosophy of Reflection. USA: Harvard University Press.

Gaudin, C. (1999). Lucrèce. La lecture des choses. Paris: Éditions Encre marine.

Goldgaber, D. (2018). "The Plasticity of Writing»: Malabou on the Limits of Grammatology en Wormald, Thomas and Dahms, Isabell (eds) Thinking Catherine Malabou. Passionate Detachments. London: Rowman \& Littlefield International Ltd.

Graff, P. (2014). La "déviation» dans l'épicurisme. Entre Hasard et nécessité. Paris: Éditions Aletheis.

Hooft, G. (2001). Las partículas elementales. En busca de las estructuras más pequeñas del universo. Barcelona: Editorial Crítica.

Kant, I. (2002). Crítica de la razón pura. Madrid: Taurus.

-. (1946). "Prefacio» en Historia natural y teoría general del cielo. Buenos Aires: Editorial Lautaro. 
Kirk, G.S; Raven, J. E y Schofield, M. (1987). Los filósofos presocráticos. Historia critica con selección de textos. Parte I. Editorial Gredos.

Lacan, J. (1966). «L'instance de la lettre dans l'inconscient ou la raison depuis Freud» en Ecrits. Paris: Le Seuil.

Lacoue-Labarthe, P. \& Nancy, J.-L. (1973). Le titre de la lettre. Une lecture de Lacan. Paris: Éditions Galilée.

Lange, F. (1903). Historia del materialismo. Madrid: Editorial Daniel Jorro.

Leibniz, G. (1992). Disertación acerca del arte combinatorio. Santiago de Chile: CIP Pontificia Universidad Católica de Chile.

Lenin, V. I. (1974). Materialismo y empiriocriticismo. Madrid: Editorial Fundamentos.

Lévinas, E. (1961). Totalité et Infini, Essai sur l'extériorité. M. Nijhoff, L’Haya.

Malabou, C. (2004). La plasticité au soir de l'écriture. Paris: Éditions Léo Scheer. [Trad. Javier Bassas y Joana Masó. La plasticidad en el atardecer de la escritura. Ellago Ediciones, Castellón, 2008].

-. (2010). La plasticidad en espera. Santiago: Editorial Palinodia.

-. (2014). Avant demain. Épigenèse et rationalité. Paris: P.U.F.

Marrati-Guénoun, P. (1998). La genèse et la trace. Derrida lecteur de Husserl et Heidegger. Dordrecht / Boston / London, Kluwer Academic Publishers.

Martin, J.-C (2013). Derrida. Un démantèlement de l'Occident. Paris: Max Milo Éditions.

Megino, C. (2002). «El origen de la idea de vacío en Grecia». ÉNDOXA: Series Filosóficas, n. 16.

Morel, P.-M. (1996). Démocrite et la recherche des causes. Éditions Klincksieck.

Peñalver, P. (1990). La desconstrucción. Escritura y diferencia. Barcelona: Montesinos editor.

Salem, J. (22002). Démocrite. Grains de poussièrre dans un rayon de soleil. Paris: Librairie philosophique J. Vrin.

-. (2014). Démocrite, Épicure, Lucrèce. La vérité du minuscule. Paris: Éditions Les Belles Lettres.

Sauvanet, P. (1999). Le rythme grec. D'Héraclite à Aristote. Paris: Presses Universitaires de France.

Trujillo, I. «La digresión: Malabou, Derrida y el concepto vulgar del tiempo» en: Revista de Humanidades. Universidad Andrés Bello (Chile), n 39 (enero-junio 2019), pp. 165-185.

Vernant, J.-P. (1974). Mythe et société en Grèce ancienne. Paris: Maspero. [Traducción: Mito y sociedad en la Grecia antigua. Siglo XXI editores, Madrid, $\left.{ }^{4} 2003\right]$.

Von Amelunxen, H. \& Wetzel, M. (2008). «La fotografía, copia, archivo, firma. Entrevista con Jacques Derrida» en Minerva: Revista del Círculo de Bellas Artes, n. ${ }^{\circ}$ 7, p. 81.

Wismann, H. (2010). Les avatars du vide. Démocrite et les fondements de l'atomisme. Paris: Hemann éditeurs.

[Artículo aprobado para publicación en febrero de 2020] 